\title{
Copyright Explainer \\ Why Must a Copyrighted Work Be Fixed?
}

Benjamin J. Keele, Indiana University Robert H. McKinney School of Law

colum $\rightarrow$

fter writing for a time about law library publishing, I have decided to pivot to copyright matters. I plan to
explain a specific issue in copyright law in each column. I think copyright is fascinating, and I hope this column
will help make copyright less mysterious, and perhaps even interesting.

Some provisions in the Copyright Act are very precise and concrete. For instance, a library must have a specific sign on photocopiers to avail itself of Section 108 's harbor from any infringement patrons may commit using the equipment. However, other provisions are less prosaic, raising questions of metaphysics. For this column, I would like to focus on one of these provisions, the requirement in Section 102 that a work (book, painting, song, and so on) be fixed in a tangible medium of expression. What does it mean to be fixed, and what is a tangible medium of expression? In this column, I will discuss the fixation requirement, and the next column will look at the tangible medium of expression requirement.

The requirement that something must be fixed is important for several reasons. First, the Patent and Copyright Clause (Article I, Section 8, Clause 8 of the US Constitution) authorizes Congress to gives authors rights in their writings, implicitly requiring that the works be written down in some way. Second, it would rather difficult to decide who had created a work or what exactly was protected by copyright if it was not recorded. Suppose you and I both think of the same lyrics for a song (while this is improbable, independent creation of two identical copyrightable works is possible, but we will set that aside for now). You write the lyrics down, but I just keep singing them to myself while taking my daily morning walk.

You have a copyrightable work in the lyrics, while I do not. I do not have a required writing, and I have no way of proving that I had created the lyrics independently. But I had the lyrics in my head the entire time! Memories and thoughts in one's mind are not regarded as fixed, which seems fair to me, given how fluid my memories tend to be. Also, I would have no solid evidence I created the lyrics myself. Even if we had the technology, I would prefer my brain not be considered a record the court needs to examine to decide copyright claims.

The fixation requirement has caused some problems for digital technologies. To be fixed, a work has to be stable for more than a transitory duration. When I view a website in a browser, the browser often caches some of the content to enable faster viewing, and when I listen to music on Spotify, my computer keeps some of the music in a buffer to avoid skipping. Computers make many copies of whatever data it is working with, whether on the hard drive or in the random-access memory (RAM). MAI Systems Corp. v. Peak Computer, Inc., 991 F.2d 211 (9th Cir. 1993), held that loading software into RAM for diagnostic purposes created a copy that was sufficiently fixed for copyright purposes. The case has been distinguished by some courts, and William Patry argues the holding is wrong (3 Patry on Copyright § 9:63 (Sept. 2017 update)), but this controversy shows that a basic requirement that a copyrighted work be fixed has been challenged by new technologies. I would tend to agree with Patry on this question. A major point of RAM is that it holds the data a computer is using at any given moment, and that strikes me as too fluid and changing to meet the fixation requirement.

We have looked at why the Copyright Act requires a copyrighted work be fixed. In the next column, we will examine what is meant by a tangible medium of expression in which the work is fixed. If you thought determining if a work was fixed for more than a transitory duration was perplexing, wait until you see how courts try to decide what counts as a tangible medium.

I always enjoy discussing copyright matters. If you have any questions or ideas you would like to discuss or read about in this column, please contact me at bkeele@iu.edu. 